\title{
HIV and Young Men Who Have Sex with Men
}

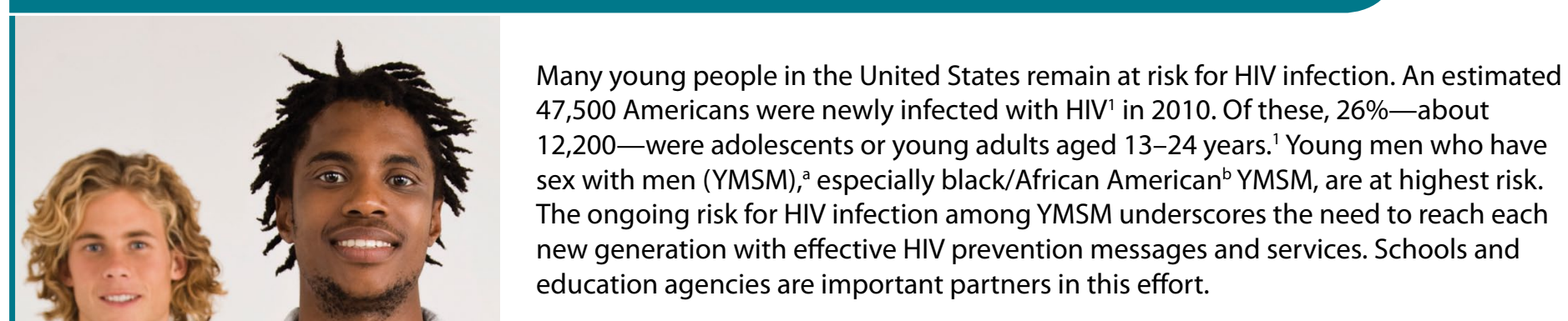

\section{Fast Facts}

HIV disproportionately affects young men who have sex with men (YMSM).

\section{YMSM:}

- In 2011, among adolescent males aged 13-19 years, approximately $93 \%$ of all diagnosed HIV infections were from male-to-male sexual contact. ${ }^{2}$

- From 2008-2011, YMSM aged 13-24 years had the greatest percentage increase (26\%) in diagnosed HIV infections. 3 (Figure 1)

Black and Hispanic/Latino' YMSM:

- In 2011, among all YMSM aged 13-24 years with HIV infection, an estimated 58\% were black; $20 \%$ were Hispanic/Latino. ${ }^{3}$

- Black YMSM also experienced the largest increase of all racial/ethnic groups in diagnosed HIV infections-from 3,762 diagnoses in 2008 to 4,619 diagnoses in 2011. ${ }^{3}$ (Figure 2)

\section{Figure 1. Diagnoses of HIV Infection among Men Who Have Sex with Men, by Age Group, 2008-2011-United States and 6 Dependent Areas}

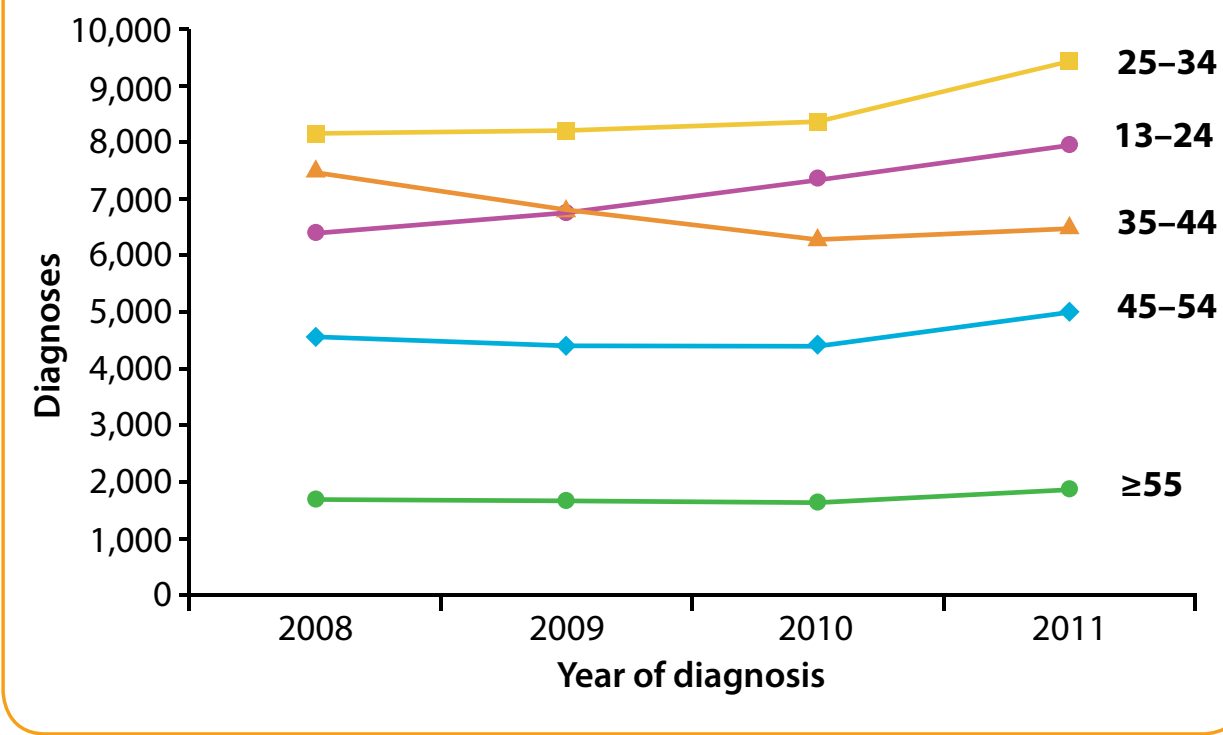

${ }^{a}$ CDC uses the term men who have sex with men (MSM) in its surveillance systems. MSM indicates the behaviors that transmit HIV infection, rather than how individuals self-identify in terms of their sexuality.

${ }^{b}$ Black/African American: Referred to as black in this fact sheet.

${ }^{\mathrm{c}}$ Hispanics/Latinos can be of any race. 
Figure 2. Diagnoses of HIV Infection Among Men Who Have Sex with Men Aged
13-24 Years, by Race/Ethnicity, 2008-2011—United States and 6 Dependent Areas

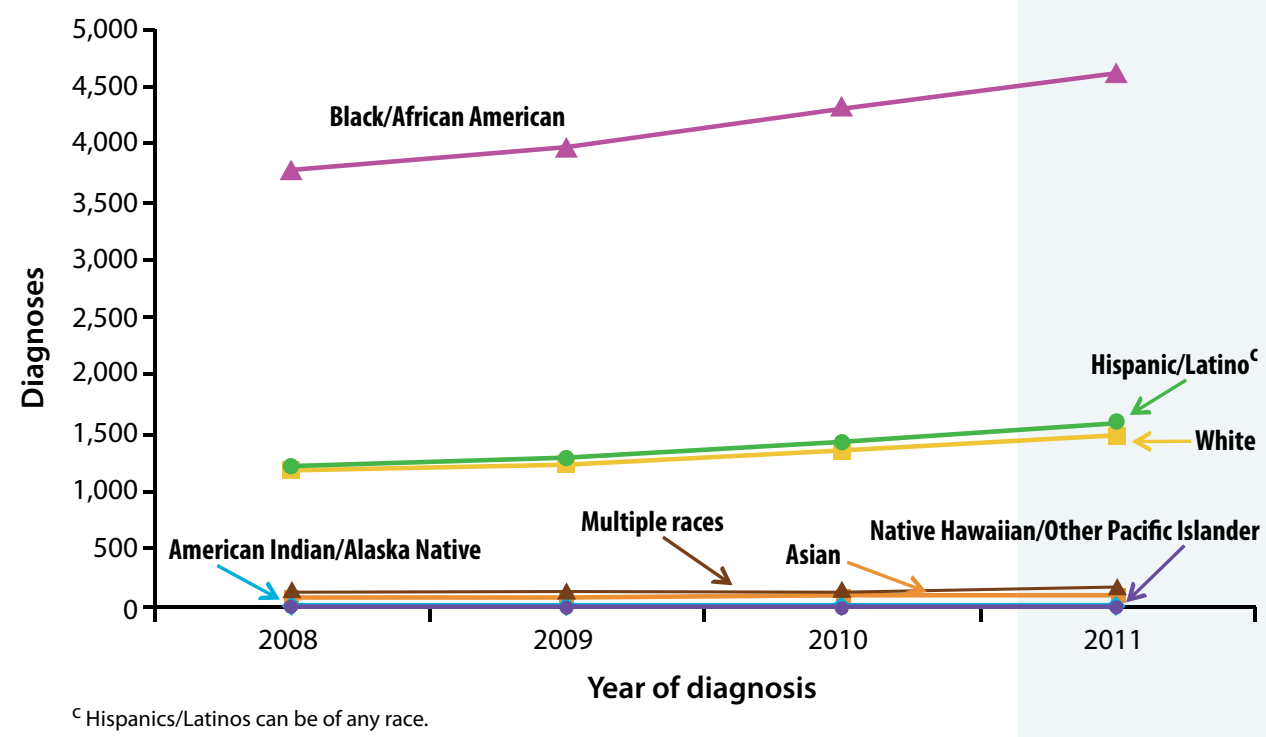

\section{HIV Prevention Challenges}

The reasons for disparities in HIV infection are varied and not well understood.

These disparities do not appear to reflect individual racial or ethnic differences in risk behaviors. ${ }^{4}$ Possible factors to explain these disparities may include the following:

- Inadequate HIV prevention education and interventions. Sex education programs that are not sensitive and appropriate to the needs of YMSM might not be effective in reducing sexual risk behaviors among those students. ${ }^{5}$

- Limited awareness of infection. Some HIV-infected men who have sex with men (MSM) may not know they are infected, especially MSM of color and YMSM. ${ }^{6}$ Those who do not know they are infected might be less likely to take measures to keep from spreading the virus to others. Getting tested for HIV is an important part of prevention.

- Low perception of risk. Improved treatment for HIV has helped many people with HIV infection live longer and healthier lives. YMSM, who did not witness the toll of AIDS in the early years of the epidemic, might view HIV as less dangerous and disregard risks and important prevention practices. ${ }^{7}$

- Alcohol and illegal drug use. Alcohol, methamphetamine (commonly known as "meth" or "crystal meth"), and other "party drug" use is common among some YMSM. Alcohol and drug use can lead to risky sexual behavior.?

- Feelings of rejection and isolation. Bullying, harassment, family disapproval, social isolation, and sexual violence are experienced frequently by YMSM and other sexual minority youth. ${ }^{\mathrm{d}}$ These experiences can cause poor self-esteem and feelings of shame and can lead to more emotional distress, suicide attempts, substance use, and risky sexual behavior. ${ }^{8-10}$

${ }^{d}$ Those who identify as gay, lesbian, or bisexual or who have sexual contact with persons of the same or both sexes. 


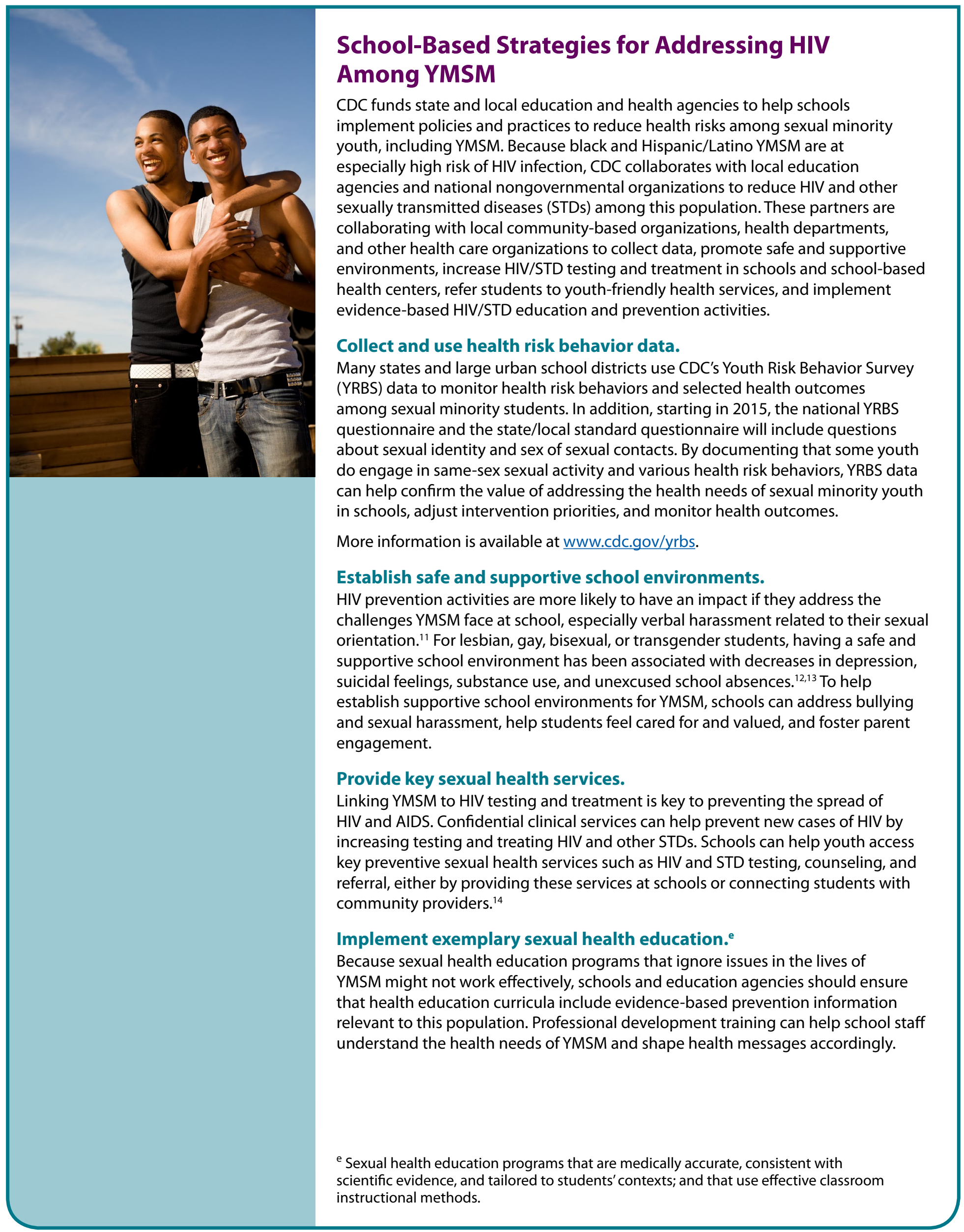




\section{HIV and YMSM Resources}

- Evidence-based HIV prevention interventions:

www.cdc.gov/healthyyouth/adolescenthealth/registries.htm

- Specific CDC-funded YMSM program activities:

www.cdc.gov/healthyyouth/disparities/ymsm/

- CDC resources on school connectedness and parent engagement in school health:

www.cdc.gov/healthyyouth/adolescenthealth/protective.htm

- Parental influence on sexual minority youth:

www.cdc.gov/healthyyouth/protective/positiveparenting/parents_influence.htm

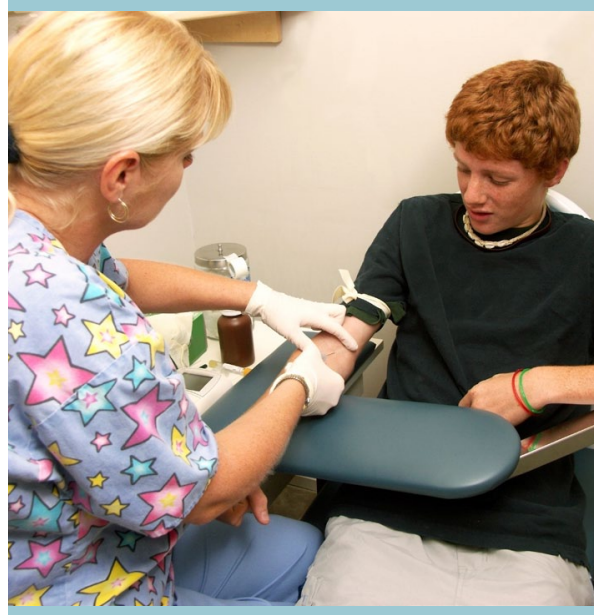

Getting tested for HIV is a critical part of prevention.

\section{References}

1. CDC. Estimated HIV incidence among adults and adolescents in the United States, 2007-2010. HIV Surveillance Supplemental Report 2012;17(No. 4). Available at www.cdc.gov/hiv/pdf/statistics_hssr_vol_17_no_4.pdf.

2. CDC. HIV surveillance in adolescents and young adults. 2012. Available at www.cdc.gov/hiv/library/slideSets/index.html.

3. CDC. HIV surveillance in men who have sex with men (MSM). 2012. Available at www.cdc.gov/hiv/library/slideSets/index.html.

4. Millett G, Flores F, Peterson JL, Bakeman R. Explaining disparities in HIV infection among black and white men who have sex with men: a meta-analysis of HIV risk behaviors. AIDS 2007;21:2083-91.

5. Blake SM, Ledsky R, Lehman T, Goodenow C, Sawyer R, Hack T. Preventing sexual risk behaviors among gay, lesbian, and bisexual adolescents: The benefits of gay-sensitive HIV instruction in schools. American Journal of Public Health 2001;91(6):940-946.

6. CDC. Prevalence and awareness of HIV Infection among men who have sex with men-21 cities, United States, 2008. MMWR 2010;59(37):1201-1207.

7. CDC. HIV and AIDS among gay and bisexual men. 2013. Available at www.cdc.gov/nchhstp/newsroom/docs/CDC-MSM-508.pdf.

8. Resnick MD, Bearman PS, Blum RW, et al. Protecting adolescents from harm: findings from the National Longitudinal Study on Adolescent Health. JAMA $1997 ; 278: 823-32$.

9. Garafolo R, Wolf RC, Kessel S, Palfrey J, DuRant RH. The association between health risk behaviors and sexual orientation among a school-based sample of adolescents. Pediatrics 1998;101:895-902.

10. Just the Facts Coalition. Just the facts about sexual orientation and youth: a primer for principals, educators, and school personnel. Washington, DC: American Psychological Association;2008.

11. Eisenberg ME, Resnick MD. Suicidality among gay, lesbian and bisexual youth: the role of protective factors. Journal of Adolescent Health 2006; 39:662-668.

12. GLSEN. The 2011 National School Climate Survey. New York: Gay, Lesbian, and Straight Education Network. 2012.

13. Espelage DL, Aragon SR, Birkett M. Homophobic teasing, psychological outcomes, and sexual orientation among high school students: What influence do parents and schools have? School Psychology Review 2008;37:202-216.

14. CDC. CDC-RFA-PS13-1308 Applicant Support Materials_Key Sexual Health Services (SHS). 2013.

Available at http://www.cdc.gov/healthyyouth/fundedpartners/1308/pdf/shs_rationale.pdf. 